\title{
LOCAL FOOD ENTREPRENEURSHIP: SEBAGAI MODEL PENGEMBANGAN KEWIRAUSAHAAN BERKELANJUTAN
}

\author{
Kartika Nuringsih $^{1 *}$, Edalmen ${ }^{2}$ \\ ${ }^{1}$ Fakultas Ekonomi \& Bisnis, Universitas Tarumanagara Jakarta \\ Email:kartikan@fe.untar.ac.id \\ ${ }^{2}$ Fakultas Ekonomi \& Bisnis, Universitas Tarumanagara Jakarta \\ Email:Edalmen@fe.untar.ac.id \\ *penulis korespondensi
}

\begin{abstract}
ABSTRAK
Selaras dengan Sustainable Development Goals (SDGs), studi ini memiliki relevansi dengan dua sasaran yaitu no poverty dan zero hunger. Hal ini berkaitan dengan kearifan pangan lokal di Kabupaten Kulon Progo, Yogyakarta yaitu "Geblek". Sampai saat ini makanan khas ini masih dapat diterima oleh masyarakat termasuk milenial di Kulon Progo sehingga sejalan dengan kedua aspek tersebut dilakukan studi tentang potensi "Geblek" sebagai local food entrepreneurship di Kulon Progo. Secara umum tujuan studi adalah mengapresiasi aktivitas komersiel maupun kewirausahaan dalam memperkenalkan "Geblek" sebagai makanan lokal sehingga perlu desain strategi pengembangan usaha dengan basis kewirausahaan berkelanjutan. Dengan demikian dilakukan studi literatur serta pengumpulan data bersama narasumber untuk mengidentifikasi atribut dalam analisis SWOT. Hasil studi mendiskripsikan local food entrepreneurship terkait dengan aktivitas komersiel makanan tradisional khas Kabupaten Kulon Progo. Dilakukan analisis potensi pengembangan local food entrepreneurship melalui analisis SWOT masing-masing empat atribut serta dirancang lima strategi pengembangan local food entrepreneurship. Hasil studi sebagai rekomendasi dalam mengkomersilkan makanan lokal melalui model local food entrepreneurship. Apresiasi ini dapat menghidupkan sektor pertanian serta menjaga kesejahteraan seluruh jaringan supply chain di kawasan pedesaan. Hal ini dirasa penting karena mengandung unsur pelestarian tradisi atau kearifan lokal masyarakat Kulon Progo sehingga relevan dengan misi keberlanjutan dengan orientasi pada keseimbangan antara nilai sosial-budaya, lingkungan hidup, dan pertumbuhan ekonomi masyarakat pedesaan.
\end{abstract}

Kata Kunci: Geblek, Keberlanjutan, Kulon Progo, Local Food Entrepreneurship

ABSTRACT

In line with the Sustainable Development Goals (SDGs), this study has relevance to two targets, namely no poverty, and zero hunger. This is related to local food wisdom in Kulon Progo Regency, Yogyakarta, namely Geblek. Until now, this special food can still be accepted by the community, including millennials in Kulon Progo, so that in line with these two aspects, a study was conducted on the potential of Geblek as local food entrepreneurship in Kulon Progo. In general, the purpose of the study is to appreciate commercial and entrepreneurial activities in introducing geblek as local food, so it is necessary to design a business development strategy based on sustainable entrepreneurship. Thus, a literature study was carried out and data collection with resource persons to identify the attributes in the SWOT analysis. The results of the study describe local food entrepreneurship related to commercial activities of traditional foods typical of Kulon Progo Regency. An analysis of the potential for developing local food entrepreneurship was carried out through a SWOT analysis with four attributes for each and five strategies for developing local food entrepreneurship were designed. The results of the study serve as recommendations for commercializing local food through the local food entrepreneurship model. This appreciation can revive the agricultural sector and maintain the welfare of the entire supply chain network in rural areas. This is considered important because it contains elements of the preservation of traditions or local wisdom of the Kulon Progo people so that it is relevant to the mission of sustainability with an orientation on a balance between socio-cultural, environmental, and economic growth at the rural communities.

Keywords: Geblek, Sustainability, Kulon Progo, Local Food Entrepreneurship 


\section{PENDAHULUAN}

\section{Latar Belakang}

Pembangunan berkelanjutan memiliki sejumlah sasaran yang harus dicapai pada 2030 dalam bentuk sustainable development goals (SDGs). Target ini sebagai apresiasi kesejahteraan generasi mendatang seperti didefinisikan World Commision on Environment Development di tahun 1987: "sustainable development is development that meets the need of the present without compromising the ability of future generations to meet their own needs". Ada 17 sasaran terbagi aspek ekonomi, sosial-budaya dan lingkungan, diantaranya no poverty \& zero hunger. Sesuai dengan United Nations Development Programs, SDGs-1 dilatarbelakangi oleh kondisi "Masih banyaknya masyarakat dunia hidup di bawah garis kemiskinan dengan penghasilan kurang dari $\$ 1.90$ per hari sehingga SDGs berupaya mengatasi masalah tersebut". Melalui pembangunan berkelanjutan diharapkan meningkatkan penghasilan serta kesejahteraan masyarakat. Demikian juga, zero hunger dilatarbelakangi kondisi "Banyak masyarakat dunia kelaparan dan kekurangan gizi dimana 1 dari 9 orang tertidur dengan rasa lapar di setiap malam sehingga SDGs berupaya mengatasi masalah tersebut". Keduanya sebagai sasaran awal sehingga ditempatkan di peringkat teratas dalam SDGs. Selaras dengan tujuan tersebut sustainability penting diapresiasi dalam berbagai sektor diantaranya kewirausahaan sebagai sustainable entrepreneurship.

Dalam konsteks sederhana entrepreneurship didefinisikan sebagai "process of changing ideas into commerciel opportunity and creating value" (Leach \& Melicher, 2012) sedangkan sustainability mengarahkan keselarasan antar dimensi dalam triple bottom line dengan tujuan mengantisipasi kemungkinan kegagalan pasar (market failure). Pendekatan ini dikaji dalam berbagai studi sebelumnya seperti Hockerts \& Wustenhagen (2010); Schaltegger \& Wagner (2011) kemudian dikembangkan model riset diantaranya seperti Majid \& Koe (2012); Koe, Omar, \& Majid (2014); Koe, Omar, \& Sa'ari (2015); Nuringsih, Nuryasman, Prasodjo, \& Amelinda (2019); Nuringsih \& Nuryasman (2020). Wirausaha diharapkan dapat mengkonversi gagasan menjadi peluang yang komersial serta menciptakan nilai tambah bagi ketiga dimensi tersebut. Sejalan dengan target di atas, upaya merealisasikan zero hunger berkaitan dengan ketersediaan pangan atau ketahanan pangan. Bagi masyarakat pedesaan yang menggantungkan pada sektor pertanian, upaya mengapresiasi pangan lokal dipastikan turut mendukung ketahanan pangan. Kreativitas pengolahan bahan pangan menjadi alternatif pangan dapat mencukupi kebutuhan sekaligus menggerakan usaha mikro-kecil di pedesaan. Kolaborasi ketersediaan sumber pangan lokal dengan kreativitas mengkomersialisasi produk pangan tersebut mendorong aktivitas komersiel di kawasan pedesaan. Perlu memperhatikan orientasi pasar dan orientasi kewirausahaan dalam pemanfatan peluang (Ie \& Pratama, 2019) sehingga semakin berkontribusi dalam peningkatan kesejahteraan masyarakat serta menekan kemiskinan di kawasan pedesaan. Peluang usaha tersebut relevan dengan gagasan local food entrepreneurship (Mars \& Schau, 2017) sehingga diperlukan kebersamaan dengan konsumen dalam pengembangan bisnis local food tersebut (Mars, 2015). Oleh karena itu, aktivitas kewirausahaan di sektor pertanian (agriculture entrepreneurial) bersentuhan dengan isu-isu keberlanjutan seperti dalam aspek triple bottom line tersebut (Sargani, Zhou, Raza, \& Wei, 2020).

Atas dasar pertimbangan tersebut, studi ini mengapresiasi usaha atau aktivitas komersial berbasis kearifan pangan lokal di Kab. Kulon Progo, Yogyakarta. Tepatnya berada di bagian barat Kota Yogyakarta, wilayah ini mayoritas berada di daerah pedesaan dan pegunungan Menoreh sehingga kehidupan ekonomi masyarakatnya bergantung pada sektor pertanian/perkebunan. Berbagai local food terbuat dari bahan pangan lokal (palawija) diantaranya masih dikenal luas oleh masyarakat yaitu "Geblek". Makanan ini berwarna putih terbuat dari pati singkong, dibentuk sedemikian rupa menyerupai angka delapan kemudian dimasak dengan cara digoreng. 
Makanan ini memiliki cita rasa gurih dengan tekstur agak kenyal dan empuk dibiasanya dinikmati selagi hangat bersama dengan besengek tempe benguk. Tidak seperti tempe-tempe lainnya, tempe ini terbuat dari kacang koro benguk (mucuna pruriens) yang tumbuh di Kulon Progo dan daerah sekitanya. Pasangan geblek dan besengek masih digemari oleh masyarakat Kulon Progo yang biasanya sebagai camilan sore atau sarapan. Meskipun pasar lokal masih menerima Geblek sebagai makanan alternatif namun tidak semua segmen masyarakat terbiasa menikmati local food tersebut sehingga untuk mempertahankan kearifan pangan lokal perlu kolaborasi dengan berbagi pihak untuk mengapresiasi dan mempromosikan makanan khas ini.

Berdasarkan studi sebelumnya, Kwil, Piwowar-Sulej, \& Krzywonos (2020) disebutkan produksi pangan lokal bermanfaat untuk mengaktifkan kewirausahaan lokal karena mulai dari aktivitas produksi sampai dengan dengan konsumsi local food melibatkan peran para wirausaha. Namun terdapat dua aspek yang harus diperhatikan yaitu marketing dan kesehatan (higienitas) dalam pengelolaan usaha makanan lokal tersebut. Sebelumnya, Coelho, Coelho, \& Egerer (2018) mengarisbawahi bahwa konsumsi pangan lokal yang diproduksi sesuai dengan lingkungan serta menggunakan teknologi ramah lingkungan akan memberikan manfaat dan menyehatkan bagi lingkungan, perekonomian dan masyarakat. Dengan demikian dapat disimpulkan bahwa potensi pangan lokal apabila diapresiasi secara pro-lingkungan maka mulai bahan baku, pengolahan sampai dengan konsumsi dapat memberikan peluang usaha bagi wirausaha lokal sehingga dampak selanjutnya memberikan peningkatan kesejahteraan masyarakat.

Orientasi tersebut selaras dengan food sustainability atau sustainability local procurement yang merupakan program dari Food and Agriculture Organization (Scialabba, 2012). Model menekankan aspek kedekatan jarak antara proses produksi sampai dengan konsumsi (short supply chain). Selain itu berkaitan dengan kedaulatan pangan, penetapan harga secara adil serta memperhatikan kelestarian lingkungan. Sebelumnya, Marsden \& Smith (2005) menekankan pengembangan sektor pertanian dilakukan melalui networking agar dapat membangun strategi pengolahan pangan yang berkualitas serta pengembangan local branding. Melalui pendekatan kewirausahaan berbasis keberlanjutan lingkungan maka proses inovasi dapat membentuk keunggulan bagi kawasan pedesaan. Secara garis besar kajian ini menelaah potensi pengembangan kewirausahaan berbasis local food di Kulon Progo agar secara simultan dapat mempertahankan kearifan pangan lokal serta mendukung pembangunan keberlanjutan di sektor pertanian maupun kewirausahaan. Sejalan dengan orientasi tersebut, studi ini menelaah potensi pengembangan usaha geblek sebagai local food dari Kulon Progo sehingga diharapkan dapat berkontribusi mempertahankan kearifan pangan serta mendorong keberhasilan local food entrepreneurship di sekitar Kabupaten Kulon Progo.

Aspek keterbaruan dalam studi ini adalah menfokuskan pada aktivitas komersiel geblek sebagai local food di Kabupaten Kulon Progo dengan alur sebagai berikut: (1) mendeskripsikan local food entrepreneurship, (2) menganalisis potensi kekuatan, kelemahan, peluang dan ancaman dalam aktivitas komersiel local food sebagai icon entrepreneurial, dan (3) menindaklanjuti menjadi strategi mempertahankan geblek sebagai bagian kearifan pangan lokal. Manfaat studi sebagai informasi awal dalam proses mengkomersielkan geblek sebagai local food secara berkelanjutan sehingga bersinergi dengan sustainable entrepreneurship dalam pengembangan local food entreprneurship di Kulon Progo.

\section{Rumusan Masalah}

Dipastikan banyak kendala untuk mempertahankan local food sebagai aktivitas kewirausahaan. Geblek menjadi icon Kulon Progo dimana pasar lokal saat ini masih dapat menerima makanan 
tersebut. Namun keberlanjutan produk masih diragukan sehingga sebagai upaya pelestarian geblek sebagai local food maka keberadaan local food entrepreneurship sangat berperan saat ini. Meskipun demikian terdapat disparitas antara aktivitas komersiel, skala mikro (industri rumahan) dengan skala menengah (resto) sehingga perbedaan tersebut memiliki relevansi dengan tingkat inovasi dalam pengembangan usaha tersebut. Untuk itu rumusan masalah adalah:

1. Bagaimanakah gambaran aktivitas kewirausahaan dalam pengembangan geblek sebagai icon sustainability entrepreneurship bagi masyarakat Kulon Progo?

2. Bagaimanakah gambaran mengenai potensi kekuatan, kelemahan, peluang, dan ancaman dalam mempertahankan aktivitas komersiel geblek sebagai local food di Kulon Progo?

3. Bagaimanakah desain strategi untuk mempertahankan geblek sebagai kearifan pangan lokal melalui model local food entrepreneurship di Kulon Progo?

\section{METODE PENELITIAN}

Gambar 1 menunjukan keberadaan geblek sebagai kearifan pangan lokal yang kemudian memiliki nilai ekonomi bagi masyarakat. Dilakukan analisis potensi untuk memetakan potensi tersebut dan mengembangkan menjadi desain strategi mempertahankan geblek sebagai local food. Tahapan penelitian mengacu pada gambar tersebut meliputi Pertama: Mendeskripsikan local food entrepreneurship kemudian mengembangkan identifikasi aspek internal dan eksternal kemudian mengembangkan referensi dari berbagai artikel dan jurnal penelitian. Selanjutnya dilakukan kerjasama dengan narasumber terkait dengan usaha ini. Populasi penelitian berupa seluruh pemilik usaha geblek di Kulon Progo dengan pengambilan sampel secara acak (probability sampling method). Data primer dikumpulkan melalui observasi dan wawancara secara online dengan 5 pemilik usaha dan 10 konsumen terkait alasan suka dengan makanan ini, sedangkan data sekunder melalui berita online. Beberapa sentral produksi geblek terpilih sebagai lokasi observasi diantaranya sepanjang Nanggulan, Clereng dan sekitar kota Wates.

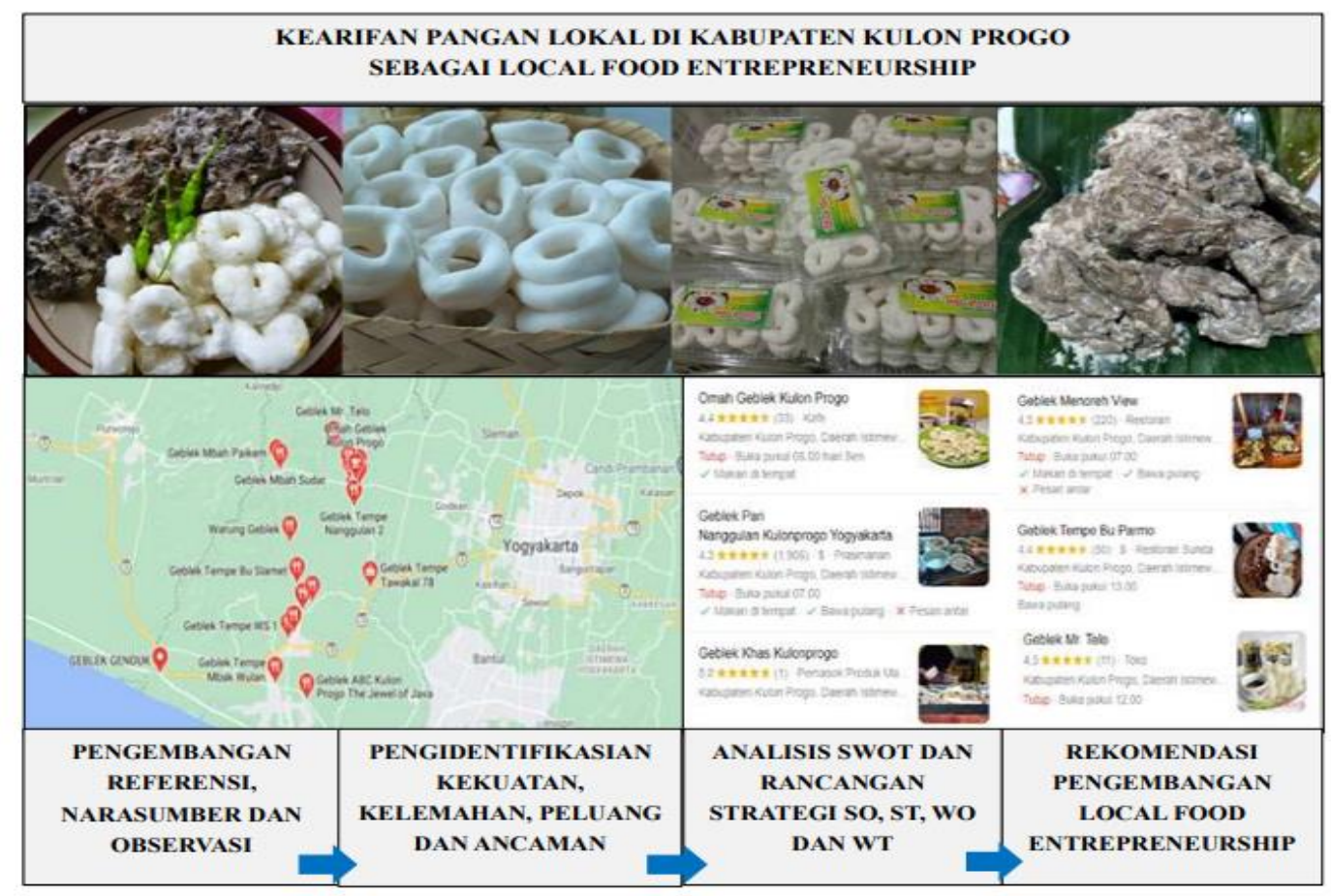

Gambar 1. Tahapan Penelitian

Sumber: Disusun oleh Penulis, 2021 
Kedua: Melakukan pemetaan berbagai atribut dalam analisis SWOT meliputi strength, weakness, opportunity dan threat dalam pengembangan usaha geblek sebagai local food di Kabupaten Kulon Progo. Mengacu pada definisi Leach \& Melicher (2012), "SWOT analysis an examination of strengths, weaknesses, opportunities, and threats to determine the business opportunity viability of an idea". Dengan demikian, studi ini sebagai awal menelaah tentang potensi local food entrepreneuship sehingga target analisis berupa penyusunan atribut dalam empat aspek pada pendekatan SWOT tersebut.

Ketiga: Melakukan analisis SWOT dan perancangan strategi terkait dengan empat dimensi yaitu: (1) SO (Strength-Opportunity), (2) ST (Strength-Threat), (3) WO (Weakness-Opportunity), dan (4) WT (Weakness-Threat). Proses analisis dilakukan melalui pendekatan diskriptif. Hal ini sebagai langkah awal dalam mengapresiasi "geblek" sebagai local food entrepreneurship di Kabupaten Kulon Progo.

Keempat: Menyusun rekomendasi dalam pengembangan local food entrepreneurship sebagai improvisasi model sustainable entrepreneurship di Kabupaten Kulon Progo. Melalui apresiasi terhadap makanan lokal tersebut berarti menghidupkan sektor pertanian, perkebunan dan perdagangan sehingga turut menjaga kesejahteraan seluruh jaringan rantai pasokan yang pada umumnya berada di kawasan pedesaan.

\section{HASIL DAN PEMBAHASAN}

\section{Pendeskripsian Local Food Entrepreneurship}

Studi ini sebagai kajian awal dengan menitikberatkan dua target pembangunan berkelanjutan yaitu no poverty dan zero hunger dengan implementasi pada aktivitas kewirausahaan berbasis local food di Kab. Kulon Progo, Daerah Istimewa Yogyakarta. Menurut Coelho et al. (2018) pangan lokal (local food) memiliki makna bahwa makanan tersebut secara fisik ditanam dekat dengan konsumen, Martinez et al. (2010) menekankan pada jarak dengaan ilustrasi beberapa mil dari titik penjualan, diproduksi di kota yang sama, atau di negara bagian yang sama. Dengan demikian dalam pengadaan local food melibatkan rantai pasokan relatif pendek (short food supply chain). Karena terkait kriteria jarak maka beberapa negara secara spesifik memberikan batasan terhadap pengertian makanan lokal.

Sebagai informasi tersebut, Coelho et al. (2018) menyarikan beberapa kriteria yaitu: (1) di Amerika Serikat total jarak ditempuh kurang dari 400 mil dari sumber $( \pm 644 \mathrm{~km})$ atau produk diproduksi dan dipasarkan di negara bagian yang sama, (2) di Kanada, Badan Pengawas Makanan Kanada (Canadian Food Inspection Agency) istilah local food sebagai makanan diproduksi di provinsi atau wilayah penjualannya, atau makanan dijual tepat di seberang perbatasan provinsi dalam jarak $31 \mathrm{mil}(50 \mathrm{~km})$ dari provinsi atau wilayah asal, dan (3) di Perancis dengan jarak $150 \mathrm{~km}$. Selanjutnya, keberadaan local food membangun kesadaran masyarakat membeli makanan lokal dengan pertimbangan "freshness, support for the local economy, support for small farms, and environmental sustainability” (Martinez et al., 2010). Makanan diproduksi secara lokal kemudian dipasarkan pada "alternative food market" atau memiliki ciri khas suatu tempat tertentu, atau membawa nilai/makna budaya lokal tertentu (Sonnino dikutip oleh Coelho et al., 2018).

Kriteria makan lokal di Indonesia dijelaskan menurut Moerdijati Gardjito peneliti gastronomi Universitas Gajah Mada kriteria sebagai makanan khas suatu bangsa/daerah adalah: (1) memiliki kejelasan asal-usul makanan seperti sejarah, riwayat penggunaan benih/bibit tanaman, (2) menggunakan bahan setempat, (3) bahan-bahan yang diolah menjadi kuliner harus dikuasai 
masyarakat setempat, (4) menggunakan peralatan yang menjadi kenangan tersendiri bagi penduduk lokal, dan (5) cita rasa makanan wajib disukai dan digemari oleh masyarakat bahkan dirindukan ketika sedang berada di tempat lain (Fizriyani, 2017).

Dengan demikian, mengapresiasi local food memiliki sinergi dengan aspek sustainability. Selain berkontribusi terhadap "zero hunger" dan "no poverty" maka proses pengolahan dan pernyiapan bahan baku juga selaras dengan aspek keberlanjutan lingkungan. Aktivitas komersial dalam pengolahan sampai dengan pemasaran local food dipastikan melibatkan wirausaha lokal sehingga memberikan dampak positif terhadap penghasilan serta menyentuh aspek kesejahteraan sosial. Keterkaitan selanjutnya mendukung terhadap "responsibility production \& consumption" dimana dalam proses pengolahan makanan khas dipertahankan secara tradisional, sementara itu pertimbangan dari sisi konsumen dalam pembelian makanan ini karena kerinduan/kenangan atau apresiasi keberadaan makanan tersebut. Oleh karena itu, pengusaha agro-bisnis (agriculture entrepreneur) memiliki peran penting dalam memastikan ketahanan pangan serta kesejahteraan petani (Mangnus, 2019) sehingga dengan pertimbangan tersebut digunakan istilah local food entrepreneurship sebagai model pengembangan di Kulon Progo.

\section{Kewirausahaan Berkelanjutan (Sustainable Entrepreneurship)}

Istilah "sustainable entrepreneurship" terdiri sustainable dan entrepreneurship dimana sebagai konsep bisnis baru yang mengintegrasikan sustainable development dengan aktivitas bisnis (Tilley \& Young, 2009). Sebelumnya, Frederick, Kuratko, \& Hodgetts (2006) entrepreneur sebagai agen perubahan sedangkan Zimmerer, Scarborough, \& Wilson (2008), entrepreneur mampu menciptakan usaha baru, menghadapi ketidakpastian atau risiko. Model ini relevan dalam era keberlanjutan sehingga dalam upaya mensinergikan dengan program kelestarian ekosistem perlu penyempurnaan konsep menuju sustainable business. Pengertian sustainable entrepreneurship diantaranya ditegaskan Dean \& McCullen (2007) dengan definisi "Sustainable entrepreneurship as the process of discovering, evaluating, and exploiting economic opportunities that are present in the market failures." Demikian juga dengan, Cohen \& Winn (2007) mendefiniskan "Sustainable entrepreneurship as the examination of how opportunities to bring into existence future goods and services are discovered, created, and exploited, by whom, and with what economic, psychological, social, and environmental consequences". Selanjutnya, Schaltegger \& Wagner (2011) mendefiniskan "Sustainable entrepreneurship can be described as an innovative, market-oriented and personality driven from of creating economic and societal value by means of break-through environmentally or socially beneficial market or institutional innovations". Definisi tersebut saling melengkapi bahwasannya sustainable entrepreneurship berkaitan dengan (1) process of discovering-exploitation of opportunity, (2) existence future goods and services, (3) creating economic and societal value, (4) break-through environmentally or socially beneficial market. Sesuai dengan berbagai literatur tersebut disarikan tiga proses yaitu: "recognition, development and exploitation of opportunity" dalam menawarkan produk dan jasa dengan mempertimbangkan manfaat secara ekonomi, sosial dan ekologi. Dengan demikian terdapat tiga dimensi keberlanjutan dalam pengembangan kewirausahaan sehingga dengan mempertimbangkan keseimbangan triple bottom line akan turut melestarikan kearifan lokal, memastikan kesejahteraan sosial/masyarakat dan yang pasti mencapai pertumbuhan ekonomi.

\section{Geblek Sebagai Local Food dari Kulon Progo}

Paduan Geblek dan Besengek dapat dikatagorikan sebagai local food bagi Kabupaten Kulon Progo dikarenakan memenuhi kriteria sebagai makanan khas diantaranya yaitu: (1) secara asalusul terdapat di Kulon Progo meskipun ada sebagian ditemukan di perbatasan dengan wilayah 
Purworejo Propinsi Jawa Tengah. Demikian juga besengek tempe benguk juga asli Kulon Progo dimana jenis bahan bakunya banyak ditanam di sekitar Kulon Progo, (2) jenis makanan tersebut menggunakan bahan berupa singkong, pati singkong dan bumbu dapur sedangkan bahan baku atau bibit tanaman benguk juga lokal dari wilayah Kulon Progo, (3) bahan-bahan yang diolah menjadi makanan dikuasai masyarakat dibuktikan penyebaran usaha makanan ini hampir merata di Kulon Progo, (4) pengolahan kedua makanan menggunakan cara tradisional dengan peralatan khas sehingga menjadi kenangan tersendiri bagi masyarakat yang berasal dari Kulon Progo, dan (5) cita rasa geblek dan besengek sangat digemari masyarakat bahkan kaum perantauan Kulon Progo sangat merindukan dengan rasa, tekstur dan aroma pada makanan tersebut.

Seiring dengan kriteria tersebut, konsumsi masyarakat terhadap geblek masih relatif tinggi saat ini sehingga memiliki potensi dikomersielkan melalui local food entrepreneurship. Usaha geblek hampir tersebar di Kulon Progo mulai konsep sederhana/pedagang kaki lima (food street vendors) hingga konsep kuliner, diantaranya Omah Geblek, Geblek Pari dan Geblek Menoreh View. Melalui model kewirausahaan yang berkelanjutan diharapkan aktivitas usaha tersebut dapat berkontribusi dalam mengangkat kearifan pangan lokal, membangun ketahanan pangan sekaligus mendorong pertumbuhan ekonomi bagi masyarakat pedesaan.

Berdasarkan pemaparan di atas, local food entrepreneurship merupakan aktivitas kewirausahaan dalam upaya menciptakan usaha/kreasi baru dari sumber pangan lokal yang sudah dimanfaatkan secara turun-temurun oleh masyarakat sehingga hampir semua bahan baku yang digunakan merupakan hasil bumi lokal. Dalam menjalankan proses kewirausahaannya, wirausaha lokal akan berkreativitas dan berinovasi agar produk yang ditawarkan dapat diterima oleh konsumen tanpa meninggalkan histori atau nilai kultural/tradisi dari komoditas tersebut. Resiko dihadapi terkait dengan perubahan gaya hidup masyarakat ke depan yang dikuatirkan berpindah ke jenis makanan yang lebih kekinian dibandingkan tradisional. Resiko selanjutnya kemungkinan kelangkaan bahan baku dikarenakan konsentrasi masyarakat beralih pada komoditas lain yang lebih komersiel. Kewirausahaan ini mengandung unsur pelestarian tradisi atau kearifan lokal suatu masyarakat sehingga memiliki relevansi dengan misi keberlanjutan seperti orientasi nilai sosial, lingkungan hidup serta ekonomi. Terkait dengan local food di Kulon Progo relevan dengan ketahanan pangan karena berkaitan dengan produktivitas pertanian sehingga untuk mendukung keberlangsungan local food entrepreneurship tersebut harus didukung pendekatan pertanian berkelanjutan (sustainable agriculture). Dengan demikian akan berkontribusi dalam memastikan no poverty dan zero hunger. Peluang ekonomi dari Geblek dan Besengek Tempe Benguk dapat dijadikan sebagai icon local food entrepreneurship dengan basis pada sustainable entrepreneurship. Apresiasi terhadap makanan tersebut berarti menghidupkan sektor pertanian sehingga turut menjaga kesejahteraan seluruh jaringan supply chain seperti petani singkong, koro benguk, dan kelapa yang umumnya berada di kawasan pedesaan. Dengan kata lain turut menjaga keseimbangan ekosistem alam pedesaan.

\section{Potensi Sebagai Local Food Entrepreneurship}

Tabel 1 merangkum atribut potensi internal dan eksternal usaha geblek sebagai makanan khas Kulon Progo. Sebagai makanan khas, atribut kekuatan (strengths) utama terletak pada cita rasa gurih, harga terjangkau, bahan baku tersedia, cara pengolahan secara tradisional, masih banyak masyarakat mengetahui resep tersebut serta mengandung nilai kenangan (story) serta kebanggan tentang kehidupan masyarakat Kulon Progo di masa-masa sebelumnya. 
Tabel 1. Pemetaan Potensi Sebagai Local Food Entrepreneurship

Sumber: Diolah oleh Penulis

\begin{tabular}{ll}
\hline \multicolumn{1}{c}{ Kekuatan } & \multicolumn{1}{c}{ Kelemahan } \\
\hline Kualitas rasa \& harga terjangkau & Tidak tahan lama \\
\hline Keaslian bahan baku \& cara pengolahan & Disparitas antara pedagang \\
\hline Ketersediaan bahan baku & Cara pengemasan \\
\hline Penguasaan resep & Kandungan nutrisi \\
\hline Nilai kenangan/kebanggaan & Aspek pemasaran \\
\hline \multicolumn{1}{c}{ Peluang } & \multicolumn{1}{c}{ Ancaman } \\
\hline Respon pasar & Masuknya jenis makanan lain \\
\hline Apresiasi pemerintah daerah & Gaya hidup masyarakat \\
\hline Destinasi wisata & Pembangunan sektor pertanian \\
\hline Media sosial & Kriteria makanan sehat \\
\hline
\end{tabular}

Sebaliknya, atribut kelemahan (weakness) seperti tidak tahan lama, pengemasan terkadang menggunakan plastik serta nampak adanya disparitas usaha. Konsep usaha ini pada awalnya sangat sederhana misalnya dijual di pasar atau kios sederhana (street food). Namun seiring dengan perubahan selera pasar, beberapa wirausaha mulai mengembangkan usaha geblek menjadi lebih menarik diantaranya mengusung konsep resto seperti Omah Geblek, Geblek Pari, Geblek Menoreh View, dan Geblek khas Kulon Progo. Dengan demikian terlihat perbedaan mencolok antara usaha warungan sederhana, kios ataupun resto. Perbedaan ini akan berkaitan dengan aspek image, pemahaman tentang pengelolaan kualitas maupun kemampuan inovasi. Kelemahan lainnya berkaitan dengan kandungan nutrisi sehingga perlu prosedur pengolahan bahan baku untuk memastikan keamanan pangan. Selain itu aspek pemasaran masih menjadi keterbatasan untuk mempromosikan geblek secara lebih menarik.

Terkait peluang (opportunity) diantaranya (1) pasar masih menerima bukan sebatas orang tua tetapi milenial Kulon Progo masih dapat menerima atau menyukai dengan Geblek dan Besengek Tempe Benguk. (2) Pemda Kulon Progo mengapresiasi geblek sebagai local food di Kulon Progo dengan turut menampilkan konten Geblek dalam city branding Kulon Progo sebagai "The Jewel of Java" serta membrandingkan kembali melalui icon "Batik Geblek Renteng" sejak tahun 2012. Apresiasi ini sekaligus membangun image pada local food tersebut. Meskipun terbatas, produk ini juga dikembangkan oleh masyarakat di luar atau perbatasan dengan Kulon Progo tetapi image Geblek tetap melekat dengan ciri khas Kulon Progo. (3) Perkembangan destinasi wisata alam di kawasan Menoreh makin menarik sehingga menikmati Geblek dengan Kopi Menoreh terasa nikmat dinikmati wisatawan di suatu desa wisata. Selain itu makin banyak komunitas olah raga (sepeda) singgah di Kulon Progo untuk menikmati makanan tersebut. (4) Perkembangan media sosial makin pesat sehingga informasi seputar local food mudah tersebar melalui media sosial serta mempermudah dalam proses pemesanan melalui aplikasi pesan antar. Kondisi ini makin mempermudah dalam promosi serta memviralkan suatu momen ketika seseorang sedang menikmati geblek dan kopi di suasana alam pedesaan Kulon Progo.

Namun, dipastikan ada sejumlah ancaman (threats) dihadapi oleh wirausaha makanan khas. Masuknya jenis makanan atau jajanan dari luar daerah serta perubahan gaya hidup masyarakat dapat merubah pola makan atau konsumsi yang melupakan makanan tradisional. Selain itu makanan ini dimasak dengan cara digoreng sehingga mungkin dihindari oleh sebagian konsumen yang memiliki gaya hidup sehat. Untuk itu, kandungan nutrisi perlu diuji atau dianalisis oleh ahli gizi sehingga hasil pengujian dapat digunakan sebagai dasar untuk mengupgrade atau memperbaiki nilai tambah pada makanan tradisional. Terakhir, keberlanjutan pembangunan pada sektor pertanian turut menentukan ketersediaan dan kualitas bahan baku. Hal tersebut sangat 
memungkinkan hilangnya makanan lokal yang disebabkan oleh perubahan prioritas sektor pembangunan daerah.

\section{Desain Strategi Sebagai Local Food Entrepreneurship}

Oleh karena itu, beberapa rancangan diuraikan terkait dengan strategi pengembangan makanan khas Kulon Progo menjadi local food entrepreneurship. Pertama: berkaitan dengan perkembangan media sosial. Untuk itu ditampilkan dengan membuat gerai secara menarik atau representatif di destinasi wisata sekaligus mengekspose suatu konten melalui media sosial seperti YouTube atau TikTok [S-O]. Hal ini untuk membangun penasaran bagi wisatawan sehingga terbentuk intensi membeli makanan lokal tersebut. Dalam kontek tersebut konsumen cenderung iklas membeli (willing to buy) karena memiliki beberapa pertimbangan seperti: makanan dalam kondisi fresh, mendukung pembangunan ekonomi lokal, mendukung perkembangan usaha mikro atau UKM dan rantai pasokannya, serta terdapat pertimbangan untuk menjaga keberlanjutan lingkungan/sektor lainnya di Kulon Progo. Hal ini seperti pendapat Martinez et al. (2010). Pendekatan lain dilakukan dengan melibatkan konsumen sebagai pemasar. Artinya mengajak konsumen untuk saling memberi "influence" tentang local food sehingga peran konsumen tidak sekedar membeli tetapi terlibat dalam promosi produk lokal Kulon Progo. Hal seperti diuraikan sebelumnya oleh Mars (2015). Dengan demikian media sosial dapat dipergunakan sebagai Electronic Word of Mouth (EWoM) (Kristiawan \& Keni, 2020).

Kedua: membina pedagang untuk menjaga keamanan bahan pangan sampai menjadi produk akhir sebelum dikonsumsi oleh konsumen [W-T]. Jika memungkinkan pemda memberikan subsidi perbaikan tempat berjualan atau lapak agar relatif aman dari hujan, panas ataupun debu. Permasalahan umum dalam pengembangan usaha makanan lokal berkaitan dengan kesehatan atau higienitas (Kwil et al., 2020) sehingga peran dinas kesehatan sangat diperlukan untuk selalu mengingatkan tentang proses pengolahan makanan secara benar. Masih terkait dengan strategi ini, diperlukan keterlibatan ahli gizi untuk mereview kandungan nutrisi dalam makanan khas tersebut sehingga dapat menyesuaikan dengan kriteria makanan sehat.

Ketiga: memperbaiki aspek pemasaran diantaranya pengemasan untuk pesanan dibawa pulang misalnya dengan memanfaatkan hasil karya pengrajin kemasan bambu atau besek sehingga tidak menggunakan kemasan plastik atau steroform [W-O]. Selain itu mendorong aktivitas pemasaran melalui media sosial. Hal ini sesuai pendapat Hegyes, Máté, Vafaei, \& Farkas (2018), media sosial diperlukan dalam pengembangan industri gastronomi. Usaha makanan lokal sebagai bagian sektor tersebut sehingga media sosial dimanfaatkan untuk memperkenalkan berbagai informasi seperti resep warisan leluhur, sejarah menu, bumbu-bumbu tradisional, bahan baku lokal, cara pengolahan/pemasakan serta bentuk-bentuk unik dalam penyajian kepada konsumen. Dinas UMKM \& industri kreatif mendampingi dan memotivasi kreativitas pemasaran melalui media sosial dengan memperhatikan pada kualitas informasi sehingga dapat mendorong intensi konsumen dalam membeli (Sari \& Keni, 2019).

Keempat: Mempertahankan pembangunan sektor pertanian secara berkelanjutan agar dapat mempertahankan atau menjamin ketersediaan bahan baku di masa mendatang [S-T]. Hal ini berkaitan dengan rencana pembangunan jangka menengah dan jangka panjang daerah yang kemudian dituangkan dalam peraturan daerah. Hal ini seperti pendapat Martinez et al. (2010) bahwa pemerintah daerah memiliki peran melalui regulasi terkait dengan pembangunan kawasan pedesaan serta pengembangan kawasan agropolitan secara berkelanjutan. Dengan demikian pendekatan ini untuk memastikan keberlanjutan sektor pertanian, ketahanan pangan sehingga berkontribusi dengan sustainable development goals. 
Rancangan ini sebagai saran atau rekomendasi dalam upaya mengkomersialisasi makanan khas Kulon Progo melalui model local food entrepreneurship secara berkelanjutan. Hal ini sebagai upaya mengantisipasi adanya disparitas kesempatan atau market failure dalam pembangunan ekonomi regional. Hal ini juga berarti turut bersinergi dengan SDGs diantaranya memastikan no poverty dan zero hunger di antara masyarakat sehingga menjadi keunggulan kompetitif dalam pengembangan ekonomi berbasis kearifan pangan lokal. Selaras dengan studi sebelumnya (Nuringsih \& Nuryasman, 2020) bahwa Kulon Progo memiliki potensi pada model tersebut dimana atmosfer sustainability dalam konteks double bottom line ataupun triple bottom line masih dapat dipertahankan dalam sektor kewirausahan dan UMKM. Sinergi ini dapat didukung melalui regulasi "Bela-Beli Kulon Progo" sehingga terjalin keselarasan antara kearifan dalam pemanfaatan sumber pangan lokal, kearifan mengkomersialisasi sumber pangan tersebut serta kearifan dalam penyusunan regulasi daerah terkait sektor pangan. Hal tersebut merupakan peluang dalam pengembangan local food melalui sustainable entrepreneurship.

\section{KESIMPULAN DAN SARAN}

Studi ini mendiskripsikan tentang local food entrepreneurship terkait dengan aktivitas komersiel makanan tradisional khas Kabupaten Kulon Progo. Selanjutnya dilakukan analisis potensi dalam pengembangan local food entrepreneurship melalui pendekatan analisis SWOT dengan masingmasing empat atribut. Untuk itu berhasil dirancang lima strategi dalam pengembangan local food entrepreneurship dengan tujuan sebagai rekomendasi dalam mengkomersialisasi makanan khas Kulon Progo melalui pendekatan local food entrepreneurship secara berkelanjutan. Proses analisis dalam studi ini dilakukan secara deskriptif sehingga hasil kajian ini sebagai langkah awal dalam penentuan atribut Internal Factors Analysis Matrix (IFAM) maupun External Factors Analysis Matrix (EFAM) pada analisis SWOT.

Dengan demikian, studi selanjutnya akan mengembangkan atribut tersebut melalui pendekatan Quantitative Strategic Planning Matrix (QSPM) dengan melibatkan responden di Kulon Progo. Studi ini sebagai apresiasi terhadap aktivitas kewirausahaan karena mengandung unsur pelestarian tradisi atau kearifan lokal masyarakat Kulon Progo sehingga relevan dengan dimensi keberlanjutan berorientasi pada nilai sosial-budaya, lingkungan hidup dan pertumbuhan ekonomi bagi masyarakat pedesaan. Dengan demikian, melalui local food entrepreneurship diharapkan turut bersinergi dengan pencapaian SDGs diantaranya memastikan no poverty dan zero hunger sehingga icon ini dapat menjadi keunggulan kompetitif sekaligus penciptaan nilai (creation value) bagi Pemda maupun wirausaha.

\section{Ucapan Terima Kasih (Acknowledgement)}

Terima kasih kepada LPPM Universitas Tarumanagara atas kontribusinya dalam pelaksanaan penelitian dengan SPK No:543-Int-KLPPM/UNTAR/IV/2021. Terima kasih kepada responden dan Ibu Sri Wijayanti, S.Hut., M.Si. selaku sekretaris Dinas Pertanian dan Pangan Kabupaten Kulon Progo, Daerah Istimewa Yogyakarta atas masukannya di dalam proses analisis hasil.

\section{REFERENSI}

Coelho, F.C., Coelho, E.M., \& Egerer, M. (2018). Local food: Benefits and failings due to modern agriculture. Sci. Agric. 2018, 75, 84-94.

Cohen, B., \& Winn, M.I., (2007). Market imperfections, opportunity and sustainable entrepreneurship. Journal of Business Venturing 22, 29-49.

Dean, T.J., \& McMullen, J.S. (2007) Toward a theory of sustainable entrepreneurship: Reducing environmental degradation through entrepreneurial action. Journal of Business Venturing, 
22, 50-76. doi: 10.1016/j.jbusvent.2005.09.003.

Fizriyani, W (2017). https://www.republika.co.id/berita/gaya-hidup/kuliner/17/03/30/onmjzs328syarat-makanan-bisa-menjadi-khas-suatu-daerah diakses 25 Februari 2021.

Frederick, H.H., Kuratko, D.F., \& Hodgetts, R.M. (2006). Entrepreneurship Theory, Process, and Practice. 1st Asia Pasific Edition. Australia: Cengage Learning Australia Pty Limited.

Hegyes, É.G., Máté, B., Vafaei, S.A., \& Farkas, M.F. (2018). The role of social media in gastronomy industry, Applied Studies in Agribusiness and Commerce, Vol. 11, No. 2-3, 95-104. DOI: 10.19041/APSTRACT/2017/3-4/14

Hockerts, K., \& Wüstenhagen, R. (2010). Greening goliaths versus emerging davids-theorizing about the role of incumbents and new entrants in sustainable entrepreneurship. Journal of Business Venturing, 25, 481-492.

Ie, Mei., \& Pratama, V. (2019). Pengaruh orientasi kewirausahaan dan orientasi pasar terhadap kinerja pada usaha kecil dan menengah sektor ritel. Jurnal Muara Ilmu Ekonomi dan Bisnis, Vol. 3, No. 1, April, 156-164.

Koe, W-L., Omar, R., \& Majid, I.A. (2014). Factors associated with propensity for sustainable entrepreneurship. Procedia-Social and Behavioral Sciences. Vol. 130, 65-74.

Koe, W-L., Omar, R., \& Sa'ari, J.R. (2015). Factors influencing propensity to sustainable entrepreneurship of SMEs in Malaysia. Procedia-Social and Behavioral Sciences. Vol. $172,570-577$.

Kristiawan, T.A., \& Keni, K. (2020). Pengaruh packaging, social media marketing dan electronic word of mouth terhadap keputusan pembelian busana brand lokal. DeReMa (Development of Research Management), Jurnal Manajemen, Vol. 15, No. 2, 244-256.

Kwil, I., Piwowar-Sulej. K., \& Krzywonos, M. (2020). Local entrepreneurship in the context of food production: A Review. Sustainability, 12, 424, 1-21. DOI:10.3390/su12010424

Leach, J.C., \& Melicher, R.W. (2012). Entrepreneurial Finance, 4th edition. South-Western: Cengage Learning. Nelson Education, Ltd.

Majid, I.A., \& Koe, W-L. (2012). Sustainable entrepreneurship (SE): A revised model based on triple bottom line (TBL). International Journal of Academic Research in Business and Social Sciences, June, Vol. 2 No. 6, 293-310.

Mangnus, E. (2019). How inclusive businesses can contribute to local food security. Current Opinion in Environmental Sustainability, 41, 69-73.

Mars, M.M., \& Schau, H.J. (2018). What is local food entrepreneurship? Variation in the commercially and socially oriented features of entrepreneurship in the Southeastern Arizona Local Food System. Rural Sociology, Vol. 83, issue 3, 568-597. https://doi.org/10.1111/ruso.12197.

Mars, M. M. (2015). From bread we build community: Entrepreneurial leadership and the cocreation of local food businesses and systems. Journal of Agriculture, Food Systems, and Community Development, 5(3), 63-77. http://dx.doi.org/10.5304/jafscd.2015.053.005

Marsden, T., \& Smith, E. (2005). Ecological entrepreneurship: Sustainable development in local communities through quality food production and local branding. Geoforum, vol. 36, issue 4, July 2005, 440-451; https://doi.org/10.1016/j.geoforum.2004.07.008.

Martinez, S., Hand, M., Pra, M.D., Pollack, S., Ralston, K., Smith, T., Vogel, S., Clark, S., Lohr, L., Low, S., \& Newman, C. (2010). Local food systems: Concepts, impacts, and issues. USDA-Economic Research Service, Washington, DC, USA

Nuringsih, K., Nuryasman, M.N., Prasodjo, I., \& Amelinda, R. (2019). Sustainable entrepreneurial intention: the perceived of triple bottom line among female students. Jurnal Manajemen, Vol. XXIII, No. 02, 168-190. DOI: http://dx.doi.org/10.24912/jm.v23i2.472.

Nuringsih, K., \& Nuryasman, MN. (2020). Propensity for sustainable entrepreneurship of MSEs owner in Yogyakarta, Indonesia. In Urban Development and Lifestyle, 131-139. Nova, 
Social Sciences, Urban Development and Infrastructure, Urban Studies. NY.

Sari, M.I., \& Keni. (2019). Pengaruh information quality dan relationship quality terhadap uncertainty reduction dan purchase intention. Jurnal Muara Ilmu Ekonomi dan Bisnis, Vol. 3, No. 1, April, 112-121.

Sargani, G.R., Zhou, D., Raza, M.H., \& Wei, Y. (2020) Sustainable entrepreneurship in the agriculture sector: The nexus of the triple bottom line measurement approach. Sustainability, 12(3275), 1-24. doi: 10.3390/su12083275.

Schaltegger, S., \& Wagner, M. (2011). Sustainable entrepreneurship and sustainability innovation: categories and interactions. Business Strategy and the Environment Bus. Strat. Env. 20. 222-237.

Scialabba, N.E-H. (2012). Sustainability local procurement. Sustainability Pathways, FAO. https://www.researchgate.net/publication/337199739_SUSTAINABLE_LOCAL_PROCU REMENT

Tilley, F., \& Young, W. (2009). Sustainability entrepreneur: could they be the true wealth generators of the future?. Greener Management International, issue 55, 79-92.

Zimmerer, T.W., Scarborough, N.M., \& Wilson, D. (2008). Essentials of Entrepreneirship and Small Business Management. 5th edition. New Jersey: Pearson Education Inc. 